\title{
An audit of the changes in thiamine levels during higher caloric nutritional rehabilitation of adolescent patients hospitalised with a restrictive eating disorder
}

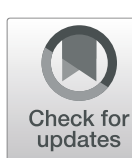

Elizabeth Parker ${ }^{1,2^{*}}$ (D), Terri Maister ${ }^{3}$, Anita Stefoska-Needham³ ${ }^{3}$ Christine Wearne ${ }^{4}$, Gail Anderson ${ }^{5}$, Linette Gomes ${ }^{5}$, Simon Clarke ${ }^{5,6,7}$ and Michael Kohn ${ }^{5,6,7}$

\begin{abstract}
Background: Routine supplementation of thiamine in patients with restrictive eating disorders prior to initiation of nutritional rehabilitation, is an example of a clinical guideline based on expert opinion rather than evidence-based recommendations. This study investigates whether adolescents hospitalised with a restrictive eating disorder commenced on a higher caloric refeeding regimen, present with or develop thiamine deficiency during their admission.

Methods: An eighteen month retrospective audit of 119 consecutive admissions for nutritional rehabilitation was conducted on patients admitted with an eating disorder in a large tertiary teaching hospital in Western Sydney. Data from paper-based and electronic medical records were collected. Baseline and weekly blood thiamine levels were documented, as well as patient demographic information including admission weight, age, length of stay, percentage median body mass index, weight change throughout admission and caloric prescription.

Results: Sixty admissions met inclusion criteria, mean age 17.2 years (SD 1.2); $88 \%$ female; BMl $16.8 \mathrm{~kg} / \mathrm{m}^{2}$ (SD 1.8) on admission. A linear mixed effects model identified that median thiamine levels increased by $9.2 \mathrm{nmol} / \mathrm{L}$ per week $(p<$ 0.001). No patient developed thiamine deficiency during their admission, one patient was admitted with thiamine levels below the normal range at $62 \mathrm{nmol}$ (normal range $67-200 \mathrm{nmol} / \mathrm{L}$ ) which resolved by the second week of admission. In 15 out of 60 patients (25\%), thiamine levels were observed to rise above the upper limit.

Conclusions: Nutritional management of 60 malnourished adolescents hospitalised with an eating disorder was conducted safely with the provision of only $10 \mathrm{mg}$ thiamine in a multivitamin daily, and no additional thiamine supplementation. The high caloric refeeding protocol, inclusive of a daily multivitamin, provided adequate thiamine to prevent thiamine deficiency. Further research should examine thiamine requirements in an exclusive severely malnourished population to assess the need for thiamine replacement in the most vulnerable group.
\end{abstract}

Keywords: Thiamine, Vitamin B1, Eating disorder, Anorexia nervosa, Nutrition

\footnotetext{
* Correspondence: Elizabeth.Parker@health.nsw.gov.au

'Department of Dietetics \& Nutrition, Westmead Hospital, PO Box 533, Wentworthville, NSW 2145, Australia

${ }^{2}$ Sydney School of Health Sciences, Faculty of Medicine and Health, The University of Sydney, Sydney 2006, NSW, Australia

Full list of author information is available at the end of the article
}

(c) The Author(s). 2020 Open Access This article is licensed under a Creative Commons Attribution 4.0 International License, which permits use, sharing, adaptation, distribution and reproduction in any medium or format, as long as you give appropriate credit to the original author(s) and the source, provide a link to the Creative Commons licence, and indicate if changes were made. The images or other third party material in this article are included in the article's Creative Commons licence, unless indicated otherwise in a credit line to the material. If material is not included in the article's Creative Commons licence and your intended use is not permitted by statutory regulation or exceeds the permitted use, you will need to obtain permission directly from the copyright holder. To view a copy of this licence, visit http://creativecommons.org/licenses/by/4.0/ The Creative Commons Public Domain Dedication waiver (http://creativecommons.org/publicdomain/zero/1.0/) applies to the data made available in this article, unless otherwise stated in a credit line to the data. 


\section{Plain English Summary}

This study looks at the change in thiamine (Vitamin B1) levels in 60 adolescent patients admitted to hospital with a restrictive eating disorder. Patients were provided with an oral meal plan with or without nasogastric tube feeding in hospital. Patients received a daily multivitamin providing $10 \mathrm{mg}$ thiamine, however did not receive an additional thiamine supplement during their hospital admission. The results of this study found that no patients developed thiamine deficiency during their hospital admission, and that the average blood thiamine level increased each week. The results of this study suggest that this group of patients hospitalised with an eating disorder received adequate amounts of thiamine through an oral meal plan with or without nasogastric tube feeding, and a daily multivitamin, and did not require an additional thiamine supplement.

\section{Background}

Nutritional management, incorporating refeeding and weight restoration (also termed nutritional rehabilitation), is a key pillar of the clinical care pathway of patients with anorexia nervosa (AN) and other restrictive eating disorders [1]. Refeeding complications can include the development the Refeeding Syndrome (RFS), and other metabolic and micronutrient changes. Shifts in electrolytes and fluid in response to increased caloric intake are implicated in the development of these complications [2].

Abnormal levels of phosphate, changes in macronutrient metabolism, as well as low extracellular levels of sodium, magnesium and potassium, are also used as markers of RFS [2]. Recently, Rio et al. (2013) [3] proposed more specific criteria for diagnosing RFS, encompassing electrolyte levels, presence of oedema and respiratory/cardiac dysfunction. In addition to RFS, thiamine deficiency (TD) is also listed as a concern when providing nutritional replenishment to malnourished patients, as severe deficiency can lead to Wernicke's encephalopathy (WE) or Wernicke Korsakoff's syndrome (WKS) [2].

In 2006, the National Institute for Health and Care Excellence (NICE) developed clinical guidelines to identify patients at risk of refeeding complications, including patients with a low body mass index $(\mathrm{BMI})<18.5 \mathrm{~kg} / \mathrm{m}^{2}$, unintentional weight loss $>10 \%$ body weight in the last 3-6 months, and a recent history of little of no nutritional intake [4]. The updated NICE guidelines recommend supplementing with $200-300 \mathrm{mg}$ oral thiamine daily prior to commencing feeding and during the first 10 days of feeding in people identified at risk of developing refeeding problems [4]. However, the paucity of scientific evidence underpinning these and other recommendations has been a key criticism of the NICE
Clinical Guidelines, in the management of patients with eating disorders $[5,6]$. There is also a growing body of evidence that challenges the 'start low, go slow' approach to renourishing patients with a restrictive eating disorder, as it has been shown to lead to the development of 'underfeeding syndrome', whereby malnourished patients are provided with insufficient energy intakes to meet basal metabolic needs and they continue to lose weight [7-12].

Routine supplementation of thiamine in patients with AN prior to initiation of nutritional rehabilitation is an example of a clinical guideline based on expert opinion rather than evidence-based recommendations [2, 4, 1315]. This practice is based on foundation knowledge of the role of thiamine as an essential cofactor in carbohydrate metabolism, an essential pathway during refeeding [2], and previous research demonstrating thiamine supplementation prior to nutritional rehabilitation may prevent TD and its associated neuropsychiatric conditions WE and WKS [16, 17]. A study of 37 patients with AN reported a $38 \%$ prevalence of TD [18], and a systematic review by Oudman E et al. (2018) identified 12 cases of TD causing WE in patients with AN ranging from BMI $12.2 \mathrm{~kg} / \mathrm{m}^{2}$ to $17.4 \mathrm{~kg} / \mathrm{m}^{2}$, including some patients with a history of alcohol and substance abuse [19].

The aim of this study is to investigate whether adolescents hospitalised with a restrictive eating disorder and commenced on a high caloric refeeding regimen, present with or develop thiamine deficiency.

\section{Methods}

\section{Study design}

A retrospective audit of 119 consecutive admissions between July 2016-December 2017 was conducted. Inclusion criteria were patients diagnosed with a restrictive eating disorder requiring nutritional rehabilitation and at least one thiamine level measured during the admission. Patients were excluded from the study if they did not have a blood thiamine level assessed during admission. Those with repeat admissions were included in the analysis if the inclusion criteria was met for subsequent admissions.

Retrospective data from paper-based and electronic medical records were collected for each admission. This included patient demographics, diagnosis, weekly weight, body mass index (BMI), weekly caloric intake, oral electrolyte supplementation received, length of hospital stay, history of purging and laxative use and any clinical signs and symptoms of refeeding syndrome and thiamine deficiency, including delirium and peripheral oedema. Baseline and weekly blood thiamine levels as well as supplement prescription were also reviewed. This study received ethical approval from the Western Sydney Local Health District Human Research and Ethics committee. 


\section{Ward program}

On admission, patients were prescribed a standardised nutritional regimen consisting of either (i) continuous nasogastric feeds with oral intake limited to sips of water, (ii) nocturnal nasogastric feeds with an oral meal plan during the day, or (iii) oral meal plan only (Fig. 1).

Patients who were considered medically unstable (presenting with bradycardia, heart rate $\leq 50 \mathrm{bpm}$, QTc interval on ECG > $440 \mathrm{~ms}$, or significantly hypotensive) were typically commenced on $1 \mathrm{kcal} / \mathrm{mL}$ formula of continuous nasogastric (NG) tube feeding to provide $2400 \mathrm{kcal} /$ day at a rate of $100 \mathrm{~mL} /$ hour, or a $1.5 \mathrm{kcal}$ formula at a rate of $35 \mathrm{~mL} / \mathrm{hr}$. for $12 \mathrm{~h}$ and then increased to $70 \mathrm{ml} /$ hr. (providing $1890 \mathrm{kcal}$ on Day 1). All oral intake other than water was restricted during the first $24 \mathrm{~h}$.

Patients with an eating disorder who were assessed as medically stable were commenced on an oral meal plan providing 1800 to $3800 \mathrm{kcal}$ with or without supplementary nocturnal NG feeds $(1 \mathrm{kcal} / \mathrm{mL}$ formula at $100 \mathrm{~mL} /$ hour for $10 \mathrm{~h}$ providing $1000 \mathrm{kcal})$. If a meal was not consumed to completion, patients were provided with additional nutritional supplements to assure prescribed caloric intake.

A patient's caloric intake was increased throughout hospitalisation by increasing meal plans $(1800 \mathrm{kcal}, 2300$ $\mathrm{kcal}, 2800 \mathrm{kcal}, 3300 \mathrm{kcal}$ and $3800 \mathrm{kcal})$, providing nutritional supplements ( $300 \mathrm{kcal}$ or $400 \mathrm{kcal})$, or altering the volume or concentration of enteral feeds (1.0, $1.5,2.0 \mathrm{kcal} / \mathrm{mL}$ formula). The total caloric intake was reviewed at least 3 times/week by the treating medical team, where decisions were made in regards to modifying the total caloric intake.

Typically, patients received prophylactic phosphate supplementation and a daily multivitamin with the commencement of the nutritional regimen. The daily multivitamin provided $10 \mathrm{mg}$ thiamine. The thiamine content in oral meal plans was $2.30-3.62 \mathrm{mg} /$ day, and the thiamine content of Enteral Formula ranged from 1.6$3.2 \mathrm{mg} / \mathrm{L}$. Serum electrolyte levels were monitored $6 \mathrm{~h}$ post nutritional intervention commencement and continued regularly until discharge. Biochemical analyses were based on the hospital reference ranges for thiamine 67-200 nmol/L. To measure thiamine levels, a commercial kit Chromsystems ${ }^{\text {tw }}$ with combined Vitamin B1/B6 Analysis UHPLC/52952 was used, with an intra-assay coefficient of variation $\leq 3.8 \%$ and inter-assay coefficient of variation $\leq 6 \%[20]$.

\section{Statistical analysis}

Descriptive analysis included patient demographics and clinical data. Number $(n)$, range, mean, standard deviation, and percentages are reported. Variables recorded

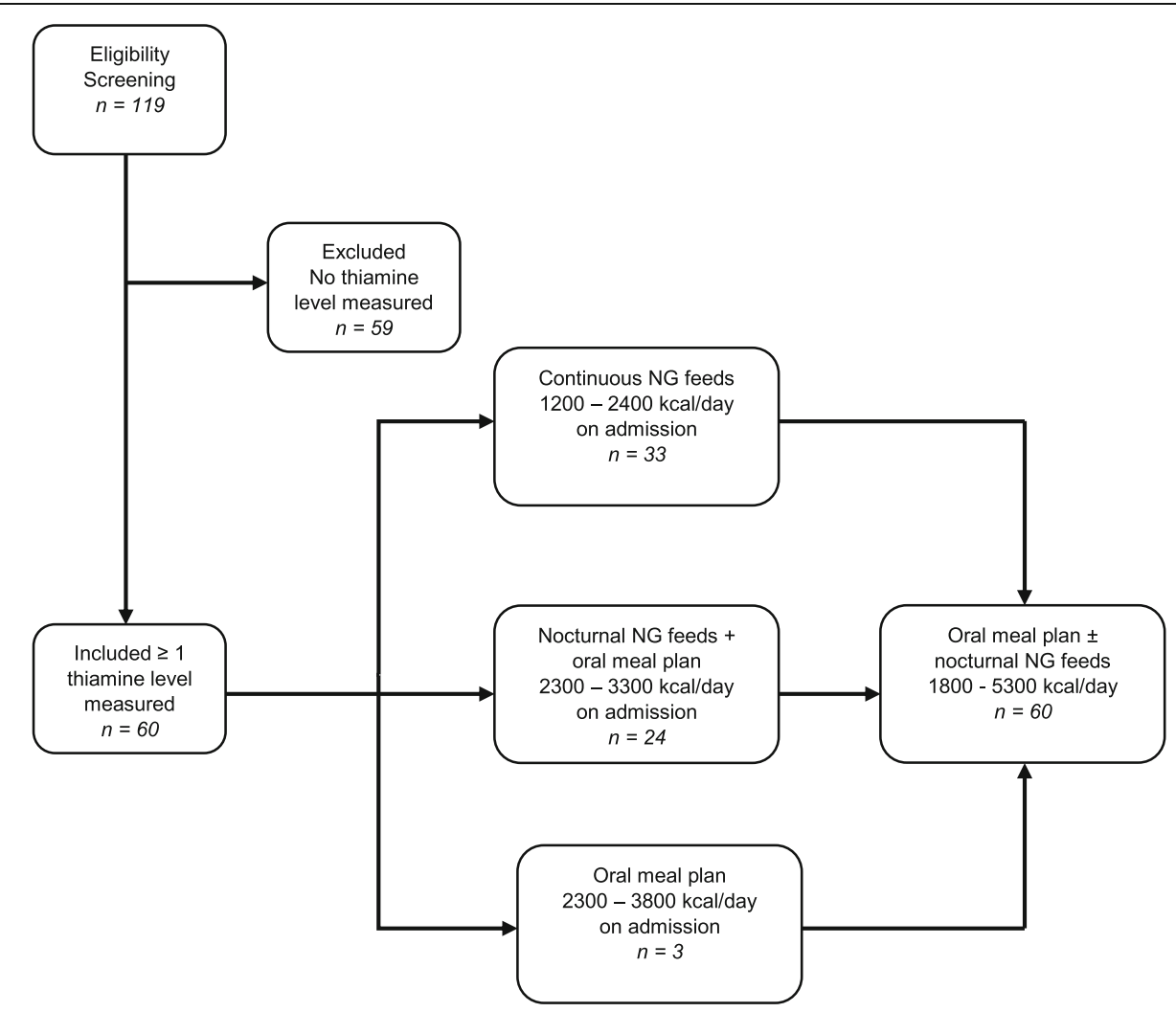

Fig. 1 Nutrition rehabilitation program provided to patients on admission and the progression to oral dietary intake 
included caloric prescription on admission, admission weight, weight change, length of hospitalisation. Percentage median BMI (\%mBMI), a calculation of the 50th percentile BMI for age and gender, was used as an indicator of malnutrition due to this being a routinely used measure in adolescent and young adult patients [21, 22].

Data were entered into SPSS for Windows Version 21, IBM Corporation and S-Plus for analysis. A linear mixed effects model conducted on thiamine trends during nutrition rehabilitation was used to analyse the data. Blood thiamine levels were assessed through data stacking. The random effect was plotted as week per individual admission. The fixed effect was weekly blood thiamine level and the value and standard error were assessed. Statistical significance was set at $p$ value $<0.05$.

\section{Results}

During the 18 month study period, 119 consecutive admissions were identified and 60 admissions (50.4\%) met the eligibility criteria for analysis (52 patients with 1 admission, 4 patients with 2 admissions). The patient cohort included 37 admissions diagnosed with DSM-5 criteria [23] for anorexia nervosa (restricting type), 14 admissions with anorexia nervosa (binge eating/purging type), and 6 admissions with Avoidant/Restrictive Food Intake Disorder. Three admissions were diagnosed with an Atypical anorexia nervosa. All patients received the daily multivitamin supplement.

Fifty-nine cases were excluded as thiamine level was not tested during their admission. Of the 60 patients included in the study, $88 \%(n=53)$ were female. On admission, mean age was 17.2 years (SD 1.2), percentage mBMI was $80.4 \%$ (SD 8.9). Patients were malnourished (11.7\% severe, $31.7 \%$ moderate, $56.7 \%$ mild) [22]. Additional patient characteristics are presented in Table 1.
Initial nasogastric (NG) tube feeding and/or oral intake was introduced and an average of $2482.0 \mathrm{kcal}$ (SD 413.2) was prescribed, and was sequentially increased during the admission (Fig. 2).

The mean thiamine level on admission was 157.5 $\mathrm{nmol} / \mathrm{L}$ (SD 36.0). During hospitalisation and nutrition intervention, median thiamine levels increased by 9.2 nmol per week (SD 2.4, IQR 4.4-14, $p$ value <0.001), based on the linear mixed effects model (Fig. 3). There was only one occasion, representing $1.7 \%$ of the study sample, when a patient had blood thiamine level recorded below the normal reference range at $62 \mathrm{nmol} / \mathrm{L}$, on admission, prior to nutrition intervention. The remaining thiamine levels on admission were all within the normal reference range of $67-200 \mathrm{nmol} / \mathrm{L}$. Over the duration of admission, 15 out of 60 patients (25\%) were observed to have a blood thiamine level greater than the upper limit of the normal reference range (200 $\mathrm{nmol} / \mathrm{L})$.

\section{Discussion}

Adolescents hospitalised with a restrictive eating disorder and commenced on a high caloric prescription did not require additional thiamine supplementation, beyond $10 \mathrm{mg}$ contained within a daily multivitamin, to maintain normal levels of thiamine during nutritional rehabilitation. Blood thiamine levels increased weekly during their admission, most likely due to thiamine intake from a daily oral multivitamin, dietary food intake and enteral feeds.

Neither low thiamine levels nor many of the proposed predisposing factors for low thiamine, are typically present for adolescents with mild to moderate malnutrition presenting with restrictive eating disorders. Nevertheless, guidelines for the nutritional management of

Table 1 Characteristics of adolescent patients hospitalised with a restrictive eating disorder (60 admissions, 56 patients)

\begin{tabular}{llc}
\hline Variable & Mean (SD) & Median (LQ-UQ) \\
\hline Age (years) & $17.2(1.2)$ & $17.2(16.4-18.1)$ \\
Admission Weight $(\mathrm{kg})$ & $45.8(7.3)$ & $45.8(41.3-51.9)$ \\
Discharge weight $(\mathrm{kg})$ & $53.4(6.6)$ & $53.6(48.9-57.0)$ \\
Admission BMI (kg/m2) & $16.8(1.8)$ & $17.1(15.8-18.3)$ \\
Discharge BMI (kg/m2) & $19.5(1.2)$ & $19.7(18.7-20.2)$ \\
Admission \%mBMl & $80.4(8.9)$ & $81.3(75.2-87.2)$ \\
Discharge \%mBMl & $93.2(6.3)$ & $94.3(89.4-97.0)$ \\
Change in \%mBMl & $12.8(6.6)$ & $12.0(7.4-16.6)$ \\
Energy intake on admission (kcal) & $2482.0(413.2)$ & $2400.0(2400.0-2800.0)$ \\
Energy intake on discharge (kcal) & $3753.3(617.7)$ & $3800.0(3400.0-3800.0)$ \\
Total weight gain (kg) & $6.9(4.4)$ & $6.1(4.2-8.9)$ \\
Average weight gain per week (kg) & $2.0(0.8)$ & $2.0(1.5-2.4)$
\end{tabular}

BMI Body mass index, \%mBMI Percentage median body mass index, LOS Length of hospital stay. 


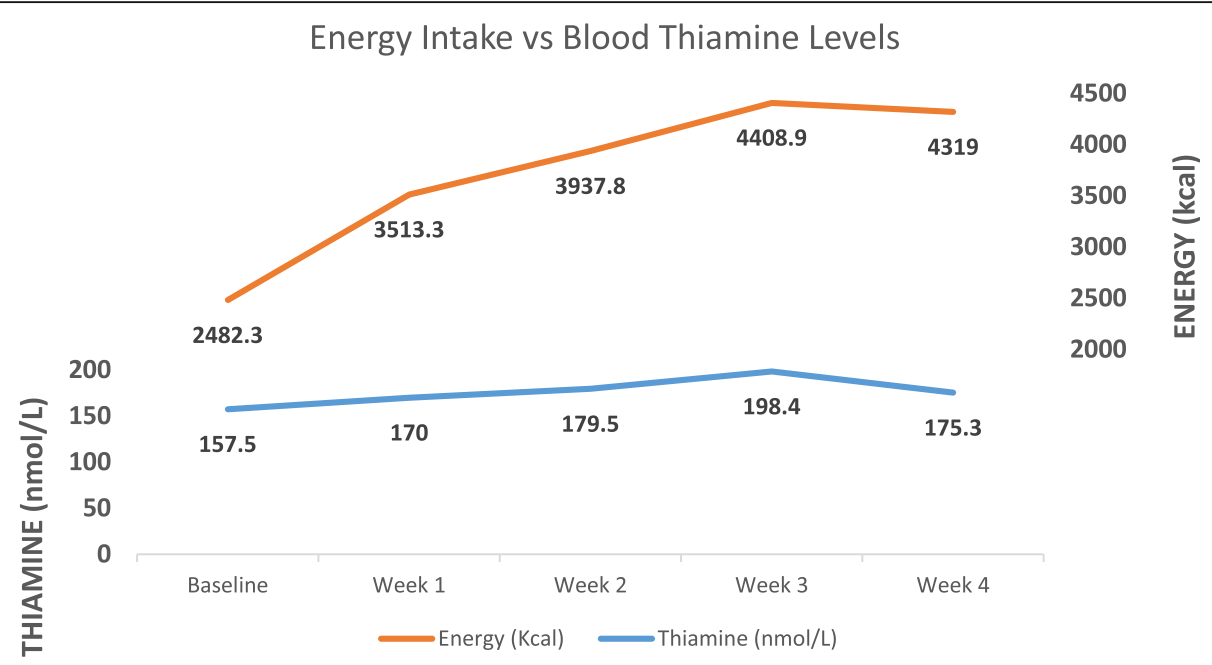

Fig. 2 Changes in energy intake and blood thiamine levels $n=60$

patients diagnosed with AN include the prophylactic supplementation of $200-300 \mathrm{mg}$ thiamine as a preventative measure for the development of refeeding complications [13]. Restriction of thiamine rich foods, excessive excretion of magnesium, and ethanol toxicity are suggested as causes for low thiamine levels and the development of WE in patients with starvation and restrictive eating disorders $[17,24-28]$. There appears to be uncertainty in the literature regarding the prevalence of thiamine deficiency observed in malnourished patients, relating to two different methods of analysis, i.e. erythrocyte transketolase activity versus measurement of blood thiamine.

Low levels of erythrocyte transketolase activity have been reported in as many as $38 \%$ of patients diagnosed with AN [18]. In the present study only one patient presented with TD on admission, as measured by blood thiamine level. The higher prevalence of thiamine deficiency in AN reported by Winston AP (2000) [18] may be explained by the use of a different method of

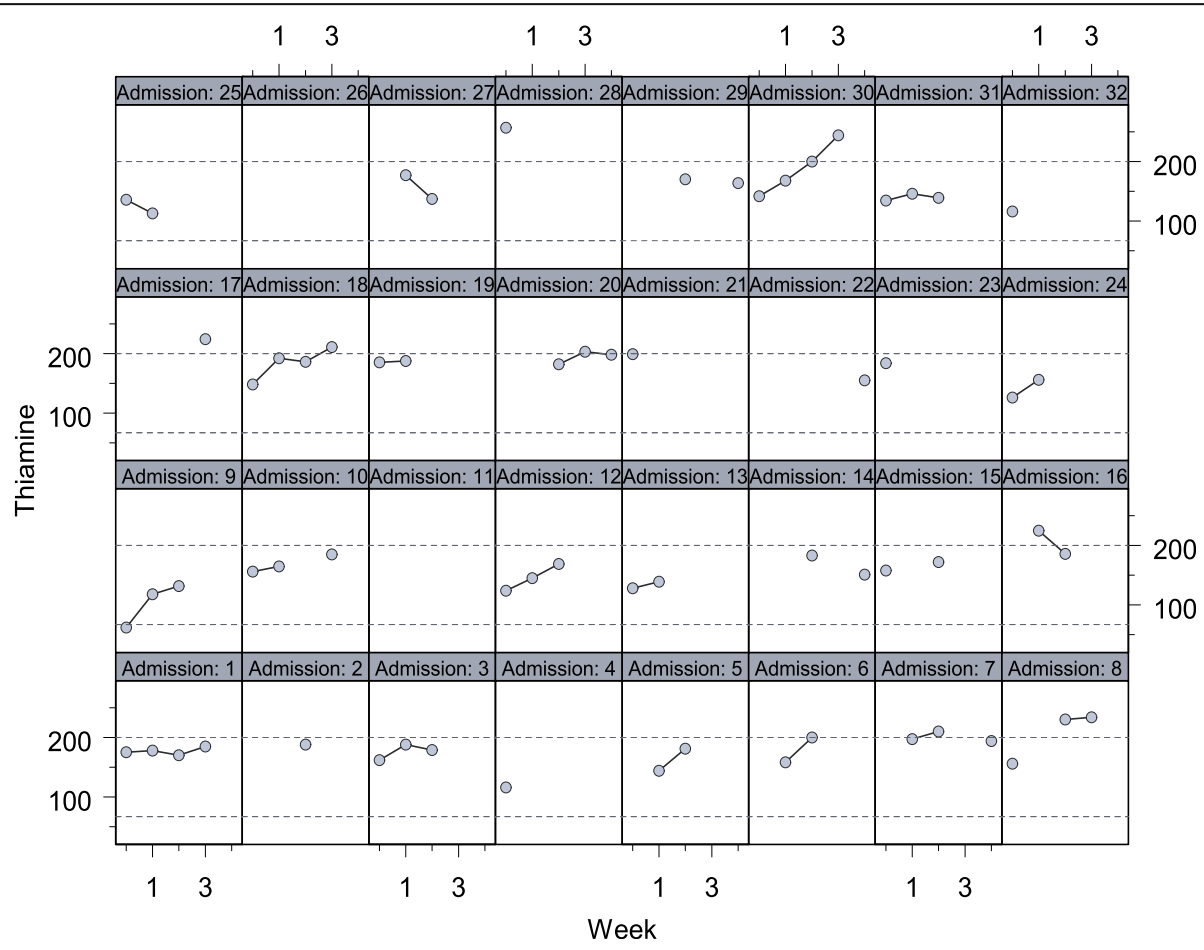

Fig. 3 Linear mixed effects model stacking patient thiamine outcome per week of Patients 1-32 
assessment in addition to investigating an older population with possibly a longer duration of illness. In their study of 37 patients, the authors reported no statistical relationship between erythrocyte transketolase activation and age, BMI, duration of restricted oral intake, frequency of vomiting, use of laxatives or alcohol consumption [18]. Reduced erythrocyte transketolase activity is likely a result of malnutrition rather than a refeeding complication, and does not necessarily infer reduced levels of thiamine.

No patients developed TD in this study. Above-RDI levels of thiamine were provided via oral meal plans, daily multivitamin supplementation and enteral feeds, as part of standard-care practices. The RDI for thiamine for patients admitted to the adolescent ward ranges from $1.1 \mathrm{mg} /$ day $-1.2 \mathrm{mg} /$ day, depending on gender and age [29], and the multivitamin alone provided patients with $10 \mathrm{mg}$ of thiamine daily (approximately 10 times the RDI). Comparison of these findings to other studies is difficult because the amount of thiamine consumed from oral intake and enteral feeds is not being routinely reported $[18,19]$.

Recommendations for the management of TD in malnourished patients continues to be influenced by guidelines for alcohol dependent patients. Thiamine deficiency in alcohol dependent individuals may result from inadequate thiamine intake, however it may also be a complication of ethanol toxicity leading to reduced intestinal absorption and bioavailability of thiamine, as well as increased thiamine requirement needed for the metabolism of alcohol [16, 17]. Furthermore, magnesium depletion has shown effects of aggravating thiamine deficiency, whereby alcohol ingestion leads to increased excretion of magnesium and may expedite the presentation of WE symptoms [24]. Guidelines for preventing refeeding complications $[2,4,30]$, including patients with $\mathrm{AN}$ [13], recommend $200-300 \mathrm{mg} /$ day thiamine supplementation, which is similar to the lower end of the range recommended in guidelines for preventing and treating TD and WE in alcohol dependent individuals which range from 200 to $600 \mathrm{mg} /$ day thiamine supplementation $[17,31,32]$.

A limitation of the present study is the absence of thiamine measurements for $49.6 \%$ of the study population, and only one method of analysis was measured. The retrospective collection of data means the study was bound by what information was documented during the admission. The current study did not identify any clinical symptoms of WE such as mental confusion or delirium, however routine assessments for ataxia and ocular motility abnormalities such as nystagmus and opthalmoplegia, are not part of routine care and may have been missed. As part of routine care, if any cases of delirium had been detected during inpatient treatment, the patient would have been referred for further investigation including clinical signs of TD. Another limitation of the study is that patients had predominantly mild to moderate malnutrition. TD and refeeding complications are more likely to develop in those with severe malnutrition, so any recommendations from this study can only apply to mild and moderately malnourished patients.

Future studies would benefit from assessing prospectively the typical symptoms of WE, including ataxia, opthalmoplegia, nystagmus and confusion on admission and throughout nutritional rehabilitation. Furthermore, future studies may consider using multiple methods for assessing thiamine status including measurement of urinary thiamine excretion as well as MRI in suspected cases of WE.

There is scope for this study to be expanded beyond an investigation of thiamine status in adolescent patients with eating disorders to include all patients who present with malnutrition and are at risk of thiamine deficiency and refeeding complications on admission. A greater sample size using a prospective study design will increase the validity of the study. Furthermore, by assessing different ages, genders and contributing comorbidities, the generalisability of the study will be expanded and translation into practice will be more impactful.

\section{Conclusions}

In conclusion, the results of the study suggest that providing high doses of thiamine through additional supplementation may be unnecessary in mild and moderately malnourished adolescents hospitalised with a restrictive eating disorder. Considering there were no cases of patients developing TD during the admission, it would suggest that patients received adequate thiamine levels through the nutritional rehabilitation program in the current study, through oral diet, enteral feeds and a daily multivitamin.

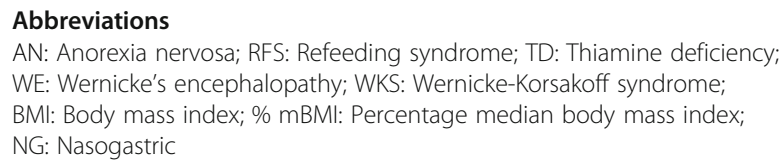

Acknowledgements

Not applicable.

\section{Authors' contributions}

$E P, S C, G A, L G$ and MK were involved in the development of the study design. TM and EP were involved in data collection and analysis. TM and EP drafted the manuscript, with contributions from ASN, CW and MK. All authors read and approved the final manuscript.

\section{Funding}

No sources of funding to declare.

Availability of data and materials

The datasets used and/or analysed during the current study are available from the corresponding author on reasonable request. 


\section{Ethics approval and consent to participate}

This study received ethical approval from the Western Sydney Local Health District Human Research and Ethics committee (Reference HREC/14/WMEAD/18).

\section{Consent for publication}

Not applicable.

\section{Competing interests}

The authors declare that they have no competing interests.

\section{Author details}

'Department of Dietetics \& Nutrition, Westmead Hospital, PO Box 533, Wentworthville, NSW 2145, Australia. ${ }^{2}$ Sydney School of Health Sciences, Faculty of Medicine and Health, The University of Sydney, Sydney 2006, NSW, Australia. ${ }^{3}$ SMART Foods Centre, School of Medicine, Faculty of Science, Medicine and Health, University of Wollongong, Wollongong, NSW 2522, Australia. ${ }^{4}$ Department of Medical Psychology, Westmead Hospital, Westmead, NSW 2145, Australia. ${ }^{5}$ Department of Adolescent \& Young Adult Medicine, Westmead Hospital, Westmead, NSW 2145, Australia. ${ }^{6}$ Sydney School of Medicine, Faculty of Medicine and Health, The University of Sydney, Sydney, NSW 2006, Australia. ${ }^{7}$ Centre for Research into AdolescentS' Health (CRASH), Adolescent \& Young Adult Medicine, Westmead Hospital, Westmead, NSW 2145, Australia.

Received: 8 April 2020 Accepted: 5 August 2020

Published online: 01 September 2020

References

1. American Psychiatric Association, Practice Guideline for the Treatment of Patients with Eating Disorders. American Psychiatric Association Publishing. 3rd ed; 2006.

2. Mehanna HM, Moledina J, Travis J. Refeeding syndrome: what it is, and how to prevent and treat it. BMJ. 2008;336:1495-8.

3. Rio A, Whelan K, Go L, Reidlinger DP, Smeeton N. Occurrence of refeeding syndrome in adults started on artificial nutrition support: prospective cohort study. BMJ Open. 2013;3(1):1-9.

4. National Institute for Clinical Excellence (NICE). "Nutrition support in adults: oral nutrition support, enteral tube feeding and parenteral nutrition," NICE Clinical Guideline 32. London: National Institute for Health and Clinical Excellence; 2006.

5. Kohn MR, Madden S, Clarke SD. Refeeding in anorexia nervosa: increased safety and efficiency through understanding the pathophysiology of protein calorie malnutrition. Curr Opin Pediatr. 2011:23:390-4.

6. Garber AK, Kohn M. Newer approaches to acute nutritional rehabilitation for patients with anorexia nervosa. Adolesc Med. 2018;29:344-58.

7. Garber AK, Sawyer SM, Golden NH, et al. A systematic review of approaches to refeeding in patients with anorexia nervosa. Int J Eat Disord. 2016:49: 293-310.

8. O'Connor G, Nicholls D, Hudson L, Singhal A. Refeeding low weight hospitalized adolescents with anorexia nervosa: a multicenter randomized controlled trial. Nutr Clin Pract. 2016;31:681-9.

9. Smith K, Lesser J, Brandenburg B, et al. Outcomes of an inpatient refeeding protocol in youth with anorexia nervosa and atypical anorexia nervosa at Children's hospitals and clinics of Minnesota. J Eat Disord. 2016:4:35

10. Parker EK, Faruquie SS, Anderson G, Gomes L, Kennedy A, Wearne CM, Kohn MR, Clarke SD. Higher caloric refeeding is safe in hospitalized adolescent patients with restrictive eating disorders. J Nutr Metab. 2016;2016:5168978. https://doi.org/10.1155/2016/5168978. Epub 2016 May 12

11. Maginot TR, Kumar MM, Shiels J, et al. Outcomes of an inpatient refeeding protocol in youth with anorexia nervosa: Rady Children's Hospital San Diego/University of California, San Diego. J Eat Disord. 2017;5:1.

12. Peebles R, Lesser A, Park CC, et al. Outcomes of an inpatient medical nutritional rehabilitation protocol in children and adolescents with eating disorders. J Eat Disord. 2017;5:7

13. The Royal College of Psychiatrists, Physicians and Pathologists, "MARSIPAN: Management of really sick patients with anorexia nervosa," College Report CR189, Council of the Royal College of Physicians, $2^{\text {nd }}$ edition, 2014.

14. Hofer M, Pozzi A, Joray M, Ott R, Hahni R, Leuenberger M, Kanel RV, Stanga Z. Safe refeeding management of anorexia nervosa inpatients: an evidencebased protocol. Nutrition. 2014;30:524-30.
15. Sobotka L. Basics in Clinical Nutrition: Refeeding Syndrome. e-SPEN. EurJournal Clin Nutr Metab. 2010;5:e146-7.

16. Frank LL. Thiamin in clinical practice. JPEN. 2015;39:503-20.

17. Sechi GP, Serra A. Wernicke's encephalopathy: new clinical settings and recent advances in diagnosis and management. Lancet Neurol. 2007;6(5): 442-55.

18. Winston AP, Jamieson CP, Madira W, Gatward NM, Palmer RL. Prevalence of thiamine deficiency in anorexia nervosa. Int J Eat Disord. 2000;28(4):451-4

19. Oudman E, Wijnia JW, Oey MJ, van Dam MJ, Postma A. Preventing Wernike's encephalopathy in anorexia nervosa: a systematic review. Psychiatry Clin Neurosci. 2018:72:774-9.

20. Chromsystems Instruments \& Chemicals GmbH. High Throughput UHPLC, combined Vitamin B1/B6 Analysis - UHPLC. Chomsystems. 2020; [cited 2020 May 27]. Available from https://www.chromsystems.com/high-throughputuhplc-combined-vitamin-b1-b6-analysis-52952-uhplc.html.

21. Centres for Disease Control and Prevention. Data table of BMl-for-age charts. 2000; Available at: https://www.cdc.gov/growthcharts/data/set1 clinical/cj411024.pdf. [cited 2020 Mar 5].

22. Golden NH, Katzman DK, Sawyer SM, et al. Position paper of the society for adolescent health and medicine: medical management of restrictive eating disorders in adolescents and young adults. J Adolesc Health. 2015;56:121-5.

23. American Psychiatric Association. Diagnostic and statistical manual of mental disorders. 5th ed. Arlington: American Psychiatric Publishing; 2013.

24. Lonsdale D. Thiamine and magnesium deficiencies: keys to disease. Med Hypotheses. 2015;84:129-34.

25. Renthal W, Marin-Valencia I, Evans PA. Thiamine deficiency secondary to anorexia nervosa: an uncommon cause of peripheral neuropathy and Wernicke encephalopathy in adolescence. Pediatr Neurol. 2014;51:100-3.

26. Pentland B, Mawdsley C. Wernicke's encephalopathy following 'hunger strike'. Postgrad Med J. 1982;58:427-8.

27. Stubbs C. Case study: refeeding syndrome and thiamin deficiency after extended starvation. Aus J Nutr Diet. 1999;56:221-3.

28. Drenick EJ, Joven CB, Swenskid ME. Occurrence of acute Wernicke's encephalopathy during prolonged starvation for the treatment of obesity. N Engl J Med. 1966:274:937-9.

29. National Health and Medical Research Council. Nutrient Reference Values for Australia and New Zealand. Australian Government and Ministry of Health, 2014.

30. Stanga Z, Brunner A, Leuenberger M, Grimble RF, Shenkin A, Allison SP, Lobo DN. Nutrition in clinical practice-the refeeding syndrome: illustrative cases and guidelines for prevention and treatment. Eur J Clin Nutr. 2008;62: 687-94.

31. Galvin R, Brathen G, Ivashynka A, Hillbom M, Tanasescu R, Leone MA. EFNS guidelines for diagnosis, therapy and prevention of Wernicke encephalopathy. Eur J Neurol. 2010;17:1408-18.

32. Haber $P$, Lintzeris $N$, Proude $E$, Lopatko $O$. Guidelines for the treatment of alcohol problems. Australian Government Department of Health and Ageing; 2009.

\section{Publisher's Note}

Springer Nature remains neutral with regard to jurisdictional claims in published maps and institutional affiliations.

Ready to submit your research? Choose BMC and benefit from:

- fast, convenient online submission

- thorough peer review by experienced researchers in your field

- rapid publication on acceptance

- support for research data, including large and complex data types

- gold Open Access which fosters wider collaboration and increased citations

- maximum visibility for your research: over $100 \mathrm{M}$ website views per year

At BMC, research is always in progress.

Learn more biomedcentral.com/submission 